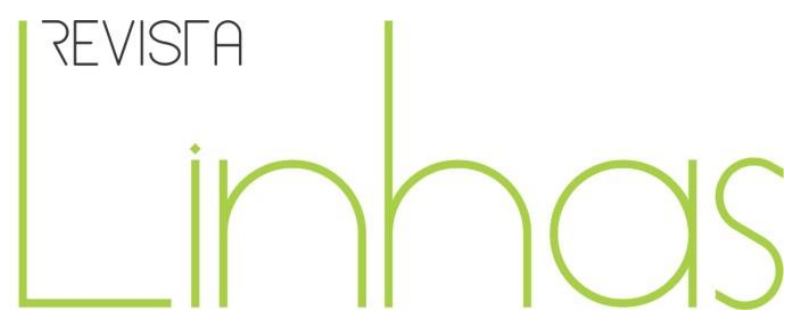

\title{
Relação educativa, avaliação e trabalho de equipe
}

\section{Resumo}

Levar em consideração as dimensões organizacionais e relacionais de um contexto educacional significa analisar aqueles fatores que, ao mesmo tempo em que desenvolvem sua fisionomia educacional, muitas vezes permanecem implícitos e irreflexivos. Nesse sentido, para adquirir e regenerar novas conscientizações sobre as implicações pedagógicas das práticas cotidianas, torna-se cada vez mais necessário promover e apoiar os processos de reflexão dentro de cada equipe pedagógica, através de uma pluralidade de perspectivas e metodologias. Deste ponto de vista, a avaliação formativa do contexto educacional é configurada como um processo dialógico e transacional, em que cada grupo de trabalho é ativo em interrogar os processos realizados e ativados com as crianças, a fim de partilhar e negociar os significados, propósitos e valores que os orientam e, portanto, adquirir uma maior conscientização, superando assim apenas um aspecto de certificação e classificação da avaliação. Em particular, ser capaz de observar, descrever e avaliar a qualidade da relação educativa, a partir da análise de alguns fragmentos de vídeo em relação aos intercâmbios de comunicação realizados com as crianças, torna-se para cada equipe educacional uma oportunidade de formação particularmente importante, pois permite analisar aspectos-chave da ação educacional, mas que podem permanecer incorporados no fluxo das rotinas diárias e relegados ao critério de cada professor. Escolhas organizacionais e modalidades relacionais que podem ser ainda interrogadas e problematizadas entrelaçando estas metodologias com abordagens baseadas no uso de estratégias de escrita reflexiva, criando assim com cada grupo educacional percursos de formação, em que diferentes olhares e conhecimentos se confrontam para co-construir repertórios de significados compartilhados e gerar novas consciências.

Palavras-chave: Relação Educativa. Avaliação Formativa. Reflexão. Colegialidade. Educação Pré-Escolar.

\author{
Antonio Gariboldi \\ Università degli Stud di Modena e \\ Reggio Emilia - Italia \\ antonio.gariboldi@unimore.it \\ Antonella Pugnaghi \\ Università degli Stud di Modena e \\ Reggio Emilia - Italia \\ antonella.pugnaghi@unimore.it
}

\section{Para citar este artigo: \\ GARIBOLDI, Antonio; PUGNAGHI, Antonella. Relação educativa, avaliação e trabalho de equipe. Revista Linhas. Florianópolis, v. 19, n. 40, p. 94-115, maio/ago. 2018. Título original: Relazione educativa, valutazione e lavoro di equipe. Traduzido por Fernando Coelho, com revisão técnica de Catarina Moro.}




\title{
Teacher-child relationship, educational evaluation and collegiality
}

\begin{abstract}
Taking into consideration the organizational and relational dimensions of an educational context means analyzing those factors that, although they draw its educational physiognomy, very often remain implicit and unaware. In this sense, to acquire and regenerate new awareness about the pedagogical implications of everyday practices, it becomes increasingly necessary to promote and support the processes of reflection within each pedagogical equipe, through a plurality of perspectives and methodologies. In this perspective, the educational evaluation of the context is outlined as a dialogic and transactive process, in which each working group is active in interrogating the processes implemented and activated with the children, in order to share and negotiate the meanings, the purposes and values that guide them and, therefore, to acquire greater awareness, thus overcoming a merely certification and classificatory view of the evaluation. In particular, being able to observe, describe and evaluate the quality of the teacher-child relationship, starting from the analysis of some video concerning the dialogues realized with the children, becomes an important training opportunity for each educational equipe to dwell on key aspects of educational action, but that they risk becoming embedded in the flow of daily routines and bound to the discretion of the individual teacher. Organizational choices and relational modalities that can be further interrogated and problematized by intertwining these methodologies with approaches based on the use of reflective writing strategies, thus realizing with each educational group the training paths, in which different perspectives and knowledge are compared to co-construct repertoires of shared meanings and generate new awareness.
\end{abstract}

Keywords: Teacher-Child Relationship. Educational Evaluation. Professional Reflectivity. Collegiality. Early Childhood Education. 


\section{Currículo e pedagogia latente na escola de educação infantil: uma}

\section{perspectiva reflexiva}

A atenção planejada à organização do contexto educacional - e, portanto, às formas de educação que se concentram no protagonismo da criança - se desenvolveu gradualmente no âmbito de uma abordagem pedagógica que concebeu o currículo educacional da escola de educação infantil como orientado em um sentido ecológico. A afirmação no campo da educação pré-escolar de teorias sobre a construção social da inteligência e uma interpretação ecológica do desenvolvimento infantil, que o vê como dinamicamente ligado às características do sistema de interação social e às propriedades do ambiente de que o sujeito é uma parte, postula como pressuposto da ação educacional a dimensão sistêmica do processo evolutivo e o papel ativo e conectivo desempenhado pela criança no interior do contexto em que ela participa.

Tal conceito implica, em termos de formação, uma maior consideração dos componentes ambientais e sociais, a valorização das modalidades de auto-organização cognitiva e sócio-afetiva da criança e uma reflexão mais cuidadosa sobre os possíveis vínculos entre os elementos formais e informais do processo educacional. Nesse sentido, no contexto de uma abordagem pedagógica que valoriza, do ponto de vista formativo, a brincadeira, a vida de relacionamento e os processos de exploração e descoberta e que atribui, principalmente, ao professor um papel de direção ambiental, é necessário desenvolver a consciência de como o entrelaçamento de variáveis organizacionais e relacionais - a organização do espaço, tempo e grupos e as dinâmicas relacionais entre adulto e crianças e entre crianças - contribua para determinar o significado e a qualidade das experiências educacionais. O risco é, de fato, que os componentes do contexto se destinem a ser uma espécie de plano de fundo da prática didática, sem considerar em profundidade o papel fundamental que desempenham na criação da fisionomia dos processos de formação.

A reflexão sobre a dimensão organizacional e relacional do setting educativo, sobre a tendência de tais dimensões para se conotar como elementos de pedagogia irrefletida e, consequentemente, orientar de forma implícita e latente o funcionamento do currículo, implica a necessidade de fazer objeto de análise e avaliação por meio da 
equipe educacional as variáveis de contexto que, de forma mais ou menos consciente, visível e projetada, contribuem para definir uma realidade escolar específica. Portanto, é necessário se referir a todos aqueles fatores materiais, relacionais e simbólicos que determinam um contexto educativo, muitos dos quais escapam a uma deliberação consciente, excedem a prática programática e tendem a delinear um currículo invisível ou oculto mais extenso e generalizado.

A atenção a essas dimensões ocultas, também de tipo relacional e simbólico, que desencadeiam a fisionomia de um contexto educacional e que têm um impacto educacional notável na aprendizagem de habitus mentais, modelos comportamentais e competências implica a referência à noção de pedagogia latente (BECCHI, 1978). Uma noção destinada a circunscrever e destacar os elementos implícitos e recônditos do setting educacional que escapam ao planejamento da intervenção formativa, mas que têm uma influência significativa na formação de atitudes e comportamentos infantis e no estímulo ao desenvolvimento de diferentes capacidades.

Por conseguinte, está presente, em graus variados nas diversas situações educativas, uma pedagogia latente conotada por critérios generalizados e modalidades de transmissão implícitas, ligadas, principalmente, a aspectos organizacionais e relacionais, que tem um significativo impacto formativo a longo prazo na criação de disposições afetivas, hábitos mentais e comportamentais. Essa presença generalizada nas escolhas organizacionais e na ação educativa ordinária "pressupõe a necessidade de considerar o quanto permanece 'latente' no decorrer da vida cotidiana: aquilo que está escondido na obviedade, aquilo que não se pensa porque habitual, aquilo que se tende a dar por certo" (PALMIERI, 2014, p. 16). Gerar ou regenerar as consciências das configurações organizacionais e dos comportamentos mais óbvios, portanto, representa um requisito que nunca está definitivamente satisfeito com o trabalho de uma equipe educacional e, consequentemente, exige o surgimento e compartilhamento do significado de ações que se reproduzam quase que automaticamente; implica um trabalho constante, recursivamente e reflexivamente retornando às ações e contextos que caracterizam a ação diária. Isso pressupõe criar as condições (tempos, oportunidades e instrumentos) para parar e recuperar a dimensão da presença nas formas em que 
trabalhamos todos os dias. Portanto, pode-se dizer que "ganhar um profissionalismo avançado significa baseá-lo em recursos de aprendizagem que permitam transitar de áreas de pré-reflexividade para áreas mais conscientes. O ganho de um pensamento crítico-reflexivo é a condição para o desenvolvimento profissional” (FABBRI, 2007, p.79).

Assim, o que foi sublinhado solicita que tenhamos uma perspectiva reflexiva sobre o currículo da escola de educação infantil, "porque a construção do currículo impõe aos docentes uma avaliação contínua da coerência entre escolhas didáticas, princípios pedagógicos e resultados alcançados no curto e no longo espaço de tempo, procurando o equilíbrio certo entre racionalidade metodológica e tensão ética, mas principalmente para limitar o peso de aspectos implícitos e irrefletidos que podem afetar negativamente o funcionamento do currículo" (FRANCESCHINI, BORIN, 2014, p. 111).

Neste perfil, a avaliação do contexto educativo se configura como instrumento de uma abordagem orientada e reflexiva para a formação da equipe educacional, pois coloca no centro da análise e reflexão a coerência entre o projeto declarado e a ação educativa, permitindo o destaque das implicações pedagógicas das práticas cotidianas e, portanto, estimulando a negociação do significado dentro do grupo, a aprendizagem transformadora e a construção de um projeto educacional mais explícito e compartilhado.

Neste caso, estamos falando de um processo de avaliação formativa fortemente caracterizado em sentido dialógico e translativo, que visa capturar os diferentes aspectos de uma realidade dinâmica na multiplicidade de pontos de vista, destacando as relações de interdependência entre os vários elementos do contexto para poder raciocinar sobre a complexidade de uma situação educacional. Consequentemente, é uma forma de investigação autorreflexiva baseada no envolvimento e participação dos professores, o que implica procedimentos sistemáticos de autoanálise da realidade educacional e orientada para o compartilhamento de um repertório interpretativo e avaliador.

Se a construção das consciências e a evolução de uma realidade educacional estão ligadas a um processo de aprendizagem que se realiza dentro de um quadro participativo, isto é, "no contexto de formas específicas de coparticipação social” (HANKS, 2006, p.10) 
o que implicam a possibilidade de negociar significados e tomar decisões, então a avaliação pode assumir um caráter realmente formativo apenas se ativa o grupo de trabalho em profundidade e o envolve em uma prática de pesquisa social. Nesse sentido, a qualidade dos processos educacionais não pode basear-se em uma lógica inspecional de controle, mas deve basear-se em uma lógica de assunção de responsabilidade que implica participação e desenvolvimento da capacidade de autorregulação. Aprender a avaliar e avaliar-se significa aprender a ativar processos de autoanálise e, portanto, aprender modalidades de controle da própria ação para evitar que se caracterize em termos de atividade irreflexiva.

Nesse sentido, uma área de desenvolvimento profissional que exige constantemente exame e pensamento, e, portanto, uma presença reflexiva em situações que são conhecidas como habituais, é a relação educativa. Uma dimensão essencial do “mundo de fazer escola" (CAPPA, 2014) que evoca e refere-se à complexidade da noção de intencionalidade educativa, entendida como um conceito que não pode ser reduzido apenas aos objetivos racionalmente definidos e perseguidos, mas como "sistemas de razões" que de modo parcialmente inconsciente e intuitivo baseiam a ação educativa do sujeito e estão conectados a toda sua experiência e à "história" que mais geralmente o envolve (COLICCHI, 2005). Assim, parece vital para adotar momentos e ferramentas que têm como objeto de análise formas de regulação do campo intersubjetivo professorcriança(s), para solicitar o exame atento daquilo que às vezes parece "mais conhecido do que pensado", estimulando um processo de questionamento das motivações do próprio trabalho, de explicitação e compartilhamento dos significados educacionais implícitos e, portanto, do aumento coletivo dos níveis de conscientização pedagógica.

Trabalhando em uma chave formativa na relação educativa implica, então, avaliála, no sentido de compreender e atribuir sentido e valor pedagógico, considerando-a como um elemento estrutural do contexto educacional, ou seja, analisando-o em suas interdependências funcionais com a organização dos espaços, materiais, tempos e regras das situações/propostas educacionais. Aqui a avaliação, que mesmo através da ativação de dinâmicas de contraste/conflito tem o objetivo da revisão das "formas óbvias" de relacionamento, está ligada à criação de um contexto de troca e discussão que, a partir da 
detecção e análise de elementos operacionais, permite a comparação entre uma pluralidade de perspectivas, fazendo emergir e tornando-se objeto de crítica as diferentes representações de "boa relação educativa".

\section{Relação educativa: é possível avaliar sua qualidade?}

Tratar de entender a complexidade que distingue cada contexto educacional significa examinar uma multiplicidade de aspectos (materiais, organizacionais, didáticos, simbólicos e de valor) intimamente interligados, mas acima de tudo significa questionar a qualidade das dinâmicas relacionais experimentadas diariamente por cada criança dentro desta realidade.

A relação educacional, entendida como uma história de interações (HINDE, 1981), ou seja, uma história de microtrocas que ocorre em contextos particulares, adotando estilos particulares (MANTOVANI, 1989), configura-se como uma relação não banal, intrinsecamente complexa, principal indicador do bom funcionamento do contexto em si.

Em particular, para explorar de forma rigorosa a natureza multidimensional dessa dimensão, precisamos adotar uma perspectiva ecossistêmica (PIANTA, 1999) em que a relação educativa é delineada como um sistema aberto e complexo, atravessado por dinâmicas específicas, mais ou menos evoluídas, mais ou menos conscientes, origem daquela infraestrutura evolutiva em que as experiências da escola são construídas.

De fato, embora se reconheça nessa relação uma dimensão essencial e nevrálgica da experiência educacional de cada contexto pré-escolar, muito frequentemente esta corre o risco de ater-se na discricionaridade dos pensamentos e ações de cada educador, sem se tornar objeto de discussão e formação dentro do grupo de trabalho educacional.

Portanto, poder observar, descrever e avaliar de forma rigorosa a qualidade das dinâmicas relacionais implementadas diariamente no interior dos diferentes contextos educacionais torna-se uma oportunidade para os vários sujeitos envolvidos para discutir um aspecto nevrálgico da experiência infantil em sua substância, sem arriscar cair em interpretações impressionistas e banais. 
Nesse sentido, a avaliação da qualidade da relação educativa constituiu a principal intenção de numerosos programas internacionais de pesquisa (PIANTA et al., 2005, 2009; LOCASALE-CROUNCH et al., 2007; CURBY et al., 2009; DOWNER et al., 2012; CABELL et al., 2013; HAMRE et al., 2013; PATTISON et al., 2014) e recentemente também em pesquisas europeias (CADIMA et al., 2010; PAKARINEN et al., 2010 2012, SALMINEN et al., 2012; VON SUCHODOLETZ et al., 2014), pesquisas em que foi adotado um dispositivo específico de observação e avaliação: Classroom Assessment scoring system (Sistema de avaliação da turma) (PIANTA; LA PARO; HAMRE, 2008).

Especificamente, afastando-se de qualquer tipo de observação target child (criança alvo), esta escala de avaliação investiga a relação educativa, concentrando a atenção em estruturas-chave gerais, operacionalizadas em descrições de pattern (modelos) comportamentais holísticos, para detectar a ecologia relacional global que caracteriza cada contexto educativo pré-escolar (DOWER; SABOR; HAMRE, 2010).

Figura 1

Os domínios e dimensões de CLASS Infant, Toddler e Pre-k (Fonte: Vitiello; Hadden, 2014, p.10)

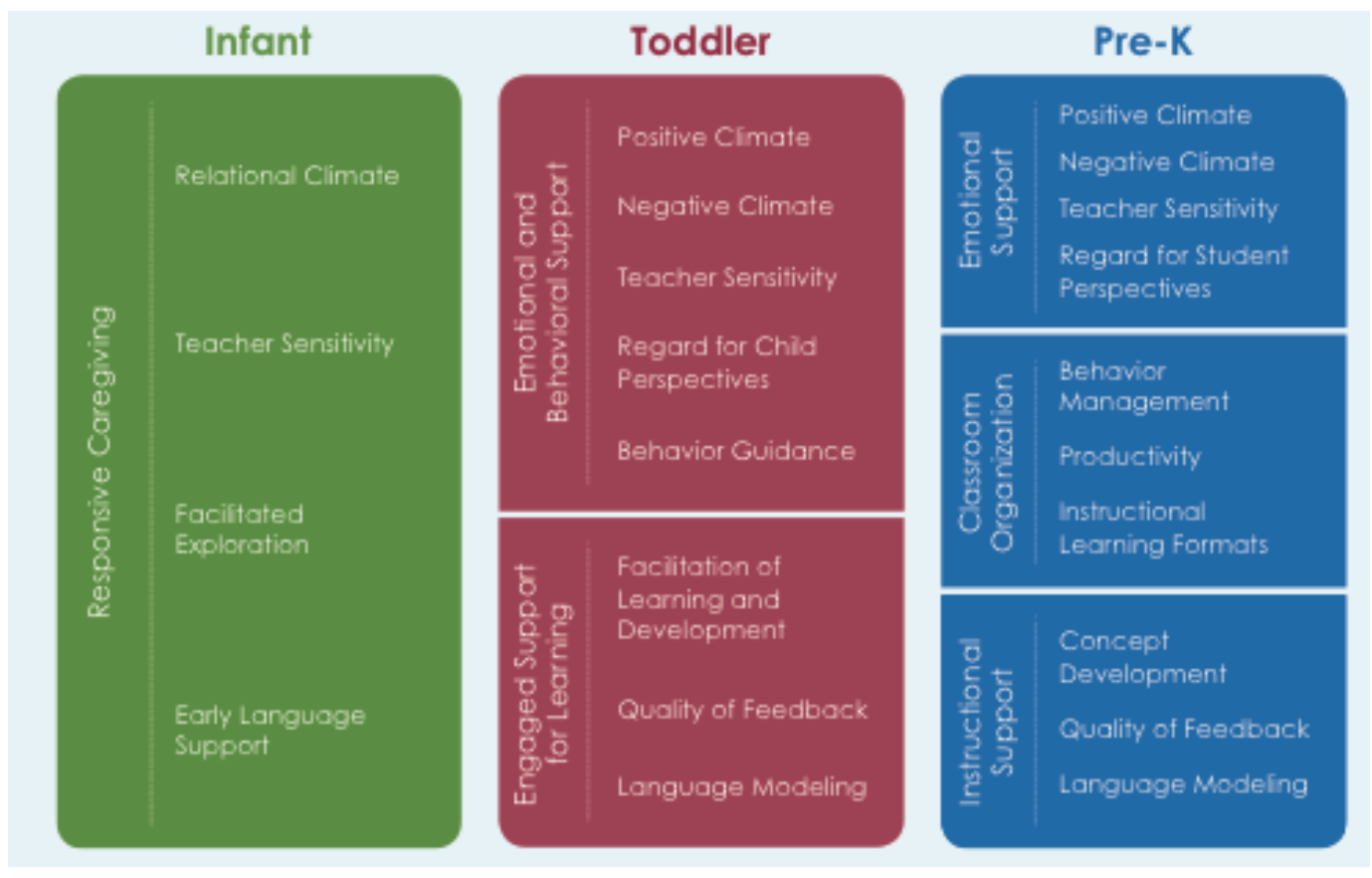


Sem querer entrar no específico, como mostrado na figura 1, a estruturação interna do dispositivo é dividida em diferentes domínios de acordo com o contexto educacional investigado, de tempos em tempos, permitindo sondar a relação educativa de acordo com uma lógica de continuidade o/6, indicando algumas estruturas-chave transversais que, com diferentes conotações de acordo com a idade das crianças, no entanto, apresentam raízes e significados compartilhados.

Nesse sentido, precisa esclarecer que, para realizar percursos reais de avaliação formativa, é necessário não se limitar a um uso técnico do instrumento de avaliação adotado, com o risco de cair em uma fruição acrítica, mas é necessário analisar e problematizar a perspectiva teórico-cultural específica nela expressa.

Nesta perspectiva, questionar e refletir sobre os critérios de avaliação delineados nesta ferramenta significa encorajar cada participante a questionar-se sobre as crenças, representações e premissas epistêmicas que muitas vezes, inconscientemente, orientam sua experiência profissional. De fato, se, por um lado, compartilhando descritores comuns e critérios de qualidade, teoricamente baseados e empiricamente validados em inúmeros percursos de pesquisa, este instrumento de avaliação é introduzida no grupo de trabalho como um conhecimento baseado no horizonte do valor provisório (MORTARI, 2009), um filtro útil para explorar até os aspectos mais emocionais e irracionais que distinguem os relacionamentos dinâmicos, por outro lado, é sempre necessário problematizar a perspectiva teórica específica sobre o qual se baseia, refletindo e questionando o modelo de relação educativa delineado nela. É, portanto, uma questão de preparar, dentro dos caminhos de avaliação formativa, momentos em que se torna possível promover um diálogo frutuoso entre o conhecimento formal expresso na escala de avaliação e proposto pelo pesquisador e o conhecimento experiencial elaborado pelos diferentes profissionais envolvidos, "como uma condição essencial para tornar o conhecimento formal vividamente útil no campo e o conhecimento da prática fundado criticamente" (MORTARI, 2009, p.107).

Nesta perspectiva, a partir de um percurso de pesquisa intitulado "Patterns educacionais na escola infantil. Uma pesquisa nas escolas de infância da província de Modena", nos últimos anos vários cursos de formação foram planejados e 
implementados visando, por um lado, os alunos do Curso de Licenciatura em Ciências da Educação Primária da Universidade de Modena e Reggio Emilia, através da estruturação de alguns laboratórios e, por outro lado, de vários grupos de trabalho educacional (professores-educadores, coordenadores e gestores), através da criação de percursos de avaliação formativa.

Especificamente, nessas últimas investigações avaliativas, o uso de CLASS pelos diferentes profissionais envolvidos é caracterizado como um espelho profissional, graças ao qual se torna possível explicitar os significados profundos, subtendidos às diferentes modalidades relacionais observadas, mas também confrontar e problematizar a filosofia de qualidade, o modelo relacional descrito e explicitado nesta escala de avaliação.

Por esta razão, torna-se interessante considerar o surgimento de alguns elementos para a reflexão nos vários encontros de feedback realizados com os diversos profissionais envolvidos, contextos formativos que, sujeitando ao escrutínio crítico o que acontece diariamente nos serviços, torna-se possível explicitar, compartilhar e problematizando esses alfabetos, repertórios cognitivos de referência e pressupostos tácitos que cada equipe educacional elabora ao longo do tempo, a fim de adquirir uma maior consciência e analisar a experiência com um novo olhar (MORTARI, 2003).

\subsection{Investigar o cuidado educativo com o CLASS}

Embora se reconheçam as características específicas que distinguem os diferentes serviços para a infância, uma dimensão essencial, que une e distingue as dinâmicas relacionais que se realizam nestes contextos, diz respeito à estrutura-chave do cuidado educacional.

Se olharmos o cuidado como a matriz de um estilo relacional que une corpo, mente e emoções (TERZI, 2017), é necessário, então, não só prestar atenção às tonalidades e às experiências emocionais que caracterizam uma boa relação educativa, mas também perceber o quanto e de que modo essas relações são importantes para a aprendizagem. 
Nesse sentido, na articulação interna do dispositivo de avaliação adotado, esta estrutura é encontrada principalmente no domínio atribuível ao Suporte Emocional, dimensão que, fazendo referência explícita à teoria do apego e da autodeterminação (BOWLBY, 1969; CONNELL; WELLBORN, 1991), considera o grau em que as crianças experimentam contextos educacionais marcados por um clima relacional positivo, no qual os relacionamentos entre pares são encorajados e onde professoras/educadoras prestam atenção aos interesses, necessidades individuais de cada criança, fornecendo a eles oportunidades reais para conversar e trabalhar de forma autônoma. Essas condições relacionais contribuem para criar aquela sensação de segurança que estimula o desejo da descoberta em cada criança, alimentando sua inesgotável sede de conhecimento (DOWER; SABOL; HAMRE, 2010).

Nesse propósito, estar em linha com o que foi afirmado no instrumento de avaliação significa que o adulto adota um estilo educacional baseado na escuta, intervenção indireta, é um diretor atento a cuidar das condições organizacionais e relacionais para que todas as crianças possam participar ativamente às suas próprias experiências de aprendizagem, promovendo processos reais de construção ativa do conhecimento.

Em particular, analisando os critérios de qualidade referentes a este campo de investigação, explicitados na versão da CLASS em relação aos contextos pré-escolares frequentados por crianças com idades entre 3 e 5 anos (pre-kindergarden), é dada atenção à centralidade da criança e à abertura e escuta, quais modalidades relacionais que devem distinguir a atitude diária de cada profissional envolvido. "Eu acho que, para cumprir bem o papel de cada um, cada professor deve permanecer disponível e aberto ao que acontece todos os dias. Porque se você assumir que tudo será de acordo com seus planos, você perde a melhor parte do nosso trabalho" (Professora).

Para os professores envolvidos, cuidar dos interesses mostrados pelas crianças e respeitar seus pensamentos também significa colocar em prática uma disponibilidade autêntica, consciente do seu papel, capaz de detectar as ideias contínuas oferecidas pelas crianças e trazê-las de volta a uma narração comum e coerente. "Se você não quiser reduzir tudo a percursos lineares e pré-empacotados que você encontra em todos os 
manuais... Você não precisa ter pensamentos estranhos ou buscar algum tipo de inovação mirabolante, mas dar valor ao que acontece no cotidiano, procurar com crianças sem achar que tudo esteja certo. Trata-se de viver tudo com o olhar curioso delas, cheio de por quê... onde nada é linear. Não devo ter medo do inesperado, na verdade é precisamente o que pode me salvar de fazer as mesmas coisas todos os dias" (Professora).

Nesta perspectiva, prestar atenção e ouvir as necessidades e os interesses das crianças se traduz em uma abertura intencional que não conduz a alguma forma de espontaneidade, pois se baseia em um projeto que consegue suportar a leitura de mundo autônoma das crianças. Nesse sentido, como diz Sergio Neri: “acima de tudo, prevalece uma atenção formidável dos professores para 'escutar' as crianças, para ler as tentativas, desejos, direções de crescimento, sem forçá-las, mas nem ser indulgentes na espera do tempo de maturação" (NERI, 2001, p. 133).

Em termo formativo, o poder descrever e compartilhar as emoções e experiências que atravessam esses difíceis equilíbrios relacionais dentro de um grupo de trabalho significa, portanto, reconhecer na pesquisa avaliativa não um momento meramente certificador e classificatório, mas uma oportunidade para aprender a para interrogar os processos realizados e ativados com as crianças, para refletir, compartilhar e negociar os significados, objetivos e valores de forma crítica e, portanto, adquirir uma maior conscientização.

Tudo isso assume ainda mais importância se se analisam essas possibilidades formativas em uma lógica de continuidade zero-seis, predispondo, então, contextos nos quais apoiar e nutrir o confronto entre os diferentes profissionais envolvidos (educadores, professores, coordenadores pedagógicos e gestores escolares), forçandoos para se concentrar em aspectos que muitas vezes podem ser incorporados no fluxo das rotinas diárias, incentivando assim novas consciências e reflexões contínuas (SAVIO, 2011; BALDUZZI; MANINI, 2013). 


\subsection{O uso de vídeos como dispositivos heurísticos e formativos}

Para evitar cair na retórica vazia e na introspecção intimista estéril e autorreferencial, é necessário ancorar a habilidade de observação e interpretação dos profissionais envolvidos na análise pontual das diferentes experiências diárias, realizadas em diferentes contextos pré-escolares examinados.

Por esta razão, em cada reunião de feedback realizada, além de apoiar as reflexões das figuras educacionais envolvidas com o uso do instrumento de avaliação (CLASS), usada como comparação, foi decidido retornar a complexidade das dinâmicas relacionais analisadas através da apreciação e análise de algumas imagens de vídeo sobre o cotidiano do serviço investigado de tempos em tempos.

Longe de qualquer forma de reducionismo técnico e aderindo à reflexão sobre os casos de vídeo propostos por Tochon (2009), o uso do vídeo constitui-se um poderoso dispositivo heurístico, capaz de estimular a reflexão construtiva sobre a prática e apoiar importantes caminhos de empowerment (capacitação) profissional através do estudo e análise dos processos que distinguem cada evento educacional. A partir da visão de alguns fragmentos de vídeo, torna-se possível, de fato, reabordar a experiência, analisar diferentes aspectos relativos não apenas aos elementos externos, como os comportamentos implementados pelos sujeitos envolvidos, mas também aos aspectos internos, ou seja, pensamentos e representações conectados a eles (CESCATO, 2015).

Reconhecendo, portanto, no vídeo uma forma de narração aberta e metacognitiva (CORAZZA, 2012), queremos preparar contextos problemáticos em que cada participante seja convidado a explorar a complexidade relacional que distingue cada evento educacional, a fim de divulgar e compartilhar os pressupostos educacionais e as implicações teóricas que atravessam e sedimentam nas práticas diárias. Nesse sentido, poder observar, descrever e avaliar a qualidade das dinâmicas relacionais que envolvem as diferentes figuras educacionais torna-se, portanto, uma oportunidade para analisar e questionar o habitual, pausar a reflexão sobre aspectos que muitas vezes escapam ao fluxo da complexidade diária (CAGGIO, 2004). Rever segmentos significativos da vida diária da escola gravada em vídeo permite que você compreenda melhor os significados 
mais profundos, pois cria uma situação de aprendizagem imersiva (WORD, 2012). Os filmados, de fato, permitem a cada participante se ver e ouvir, observar o clima geral da classe, as reações das crianças a diferentes propostas educacionais, restaurar a complexidade das situações, oferecer diferentes caminhos de leitura e interpretação e abrir novos espaços de ação.

Em resumo, "o artefato vídeo que é criado não é uma receita nem uma fórmula: é uma instantânea, um contexto para trocar ideias sobre o que acontece quando a câmera é ligada" (GOLDMAN, 2009, p. 53). Nas reuniões de restituição, as filmagens foram utilizados como pontos de partida para permitir que cada participante se reveja em ação, com foco nas trocas comunicativas e nas estratégias relacionais implementadas todos os dias com as crianças, iniciando importantes momentos de reflexão, confronto e questionamento sobre crenças e razões que frequentemente orientam tacitamente sua atividade educacional.

Neste sentido, Corazza (2012) argumenta que: "a reflexão coletiva sobre imagens gravadas pode ser útil para os atores da situação educacional para a atividade de metacognição, para distanciar-se de si e observar com espírito científico, superando a autorrefencialidade. Olhar-se em uma gravação de vídeo significa aceitar um ponto de vista diferente, o do olho da câmera e direção. Às vezes, pode ser um processo difícil e doloroso, mas sempre ajuda a reconhecer os próprios limites e identificar perspectivas de melhoria" (CORAZZA, 2012, p. 19).

Nesta perspectiva, as reuniões de feedback, o coração pulsante dos caminhos de avaliação formativa, enriquecidas por uma pluralidade de linguagens e metodologias, tornam-se verdadeiros laboratórios de desenvolvimento profissional, nos quais diferentes olhares e conhecimentos são comparados para co-construir novos conhecimentos e consciência.

Alimentar a relação recursiva entre avaliação e reflexão que é realizada nesses contextos de formação não significa querer uniformizar a um modelo relacional préestabelecido, mas garantir e valorizar as unicidades e especificidades de cada profissional envolvido, no interior de uma partilha real de valores e significados. Nesse sentido, "para 
que os docentes possam se qualificar como profissionais competentes, devem desenvolver habilidades e modos de serem necessários para se posicionar na prática como sujeitos comprometidos em fazer das suas ações objeto de uma investigação rigorosa e de uma reflexividade contínua, ou seja, eles são chamados para fazer pesquisa [...] para libertar a prática de qualquer forma de empirismo e torná-la uma ação informada por teorias criticamente construídas e verificadas empiricamente "(MORTARI, 2009, p. 20).

\section{Narrar e avaliar}

Se as modalidades descritas acima na avaliação formativa da qualidade da relação educativa se referem a vídeo-observação e ao uso crítico de uma escala de avaliação, isto é, a um instrumento que analisa de forma analítica o objeto de observação propondo alguns descritores que recusam operativamente uma ideia de "boa relação educativa", podem ser utilizadas diferentes técnicas - como alternativa ou como complemento das apresentadas - para examinar e discutir em equipe o contexto em que se atua, ativando processos de pensamento complexos. Aqui se faz referência a formas de questionar e revisar a experiência para destacar as lógicas subjacentes à ação e modalidades de documentação baseadas no uso de estratégias de escrita reflexiva. Modalidades que valorizam a narração e, portanto, a reconstrução subjetiva da experiência - em seus aspectos emocionais também - e a atenção para episódios que ocorrem em situações e circunstâncias específicas.

Neste caso, a narrativa se opõe a dispositivos de descrição sistemática e analítica de um fenômeno ou uma realidade para se propor, em vez disso, como uma forma de abordagem da experiência que permite penetrar e compreender os significados dos eventos vividos: "Narrar significa construir simultaneamente dois cenários: o da ação e o da consciência onde os significados atribuídos à ação tomam forma. [...] para saber valorizar adequadamente a atividade narrativa, é necessário estar ciente do fato de que recontar a experiência não existe um excesso de subjetivação, porque o falar sobre a 
própria experiência permite falar sobre outras coisas; na verdade, as histórias sempre dizem respeito a outra coisa" (MORTARI, 2003, pp. 82-83).

Para oferecer à equipe educacional a oportunidade de raciocinar e discutir as narrativas de eventos particulares propostos pelos membros do grupo, então, significa criar a oportunidade de avaliar, no sentido mais específico do termo, que é atribuir significado e valor, e ativar processos reflexivos em ações e relacionamentos que contribuem para definir, às vezes pelo menos em parte inconsciente, a fisionomia de contextos educacionais. Contar, analisar e problematizar a experiência e o relacionamento que temos com os outros - adultos e crianças - nos permite sentir membros de uma equipe que se comunicam intensamente entre si, renegociando o significado de práticas, compartilhando e desenvolvendo um repertório de estilos e de discursos e uma narração compartilhada sobre o valor na realidade educacional da qual faz parte. Nesse sentido, os significados do contexto são reconstruídos continuamente pelos comunicantes. E reconstruídos “através de processos comunicativos que não são redutíveis ao imediatismo comportamental, mas que também se repetem, juntamente com a mediação simbólica e a elaboração de significados pelos comunicantes individuais" (MANGHI, 2004, p. 68).

Narrar o relacionamento, em referência aos eventos mais ou menos problemáticos que surgem no cotidiano, abre a possibilidade de se concentrar e explicitar as razões por trás dos comportamentos e de questionar e negociar os pressupostos pedagógicos que estabelecem certos atos.

Deste ponto de vista, uma estratégia efetiva para solicitar a reflexão sobre a experiência no contexto de um reconhecimento individual ou grupal sobre episódios ou eventos a que um significado particular tenha sido atribuído no imediato é a de saber questionar a própria experiência através de uma série de perguntas que podemos definir generativas, em quanto promovem novos olhares no contexto relacional que se vive. De fato, "todo processo de reflexividade é ativado através da formulação de questões que o sujeito dirige para si mesmo. As questões orientam a atenção, a pesquisa e a seleção de informações e conduzem à exploração do mundo que nos rodeia" (SICORA, 2010, p. 110). O ciclo de reflexividade de Gibbs (1988) é um exemplo de uma sequência estruturada de 
questões que pode gerar reflexividade em ações e situações relacionais que, por várias razões, são consideradas importantes para a análise. Portanto, elementos significativos das relações que um professor teve com adultos e crianças podem ser objeto de questionamento e reflexão, por exemplo, a maneira pela qual um professor interveio em uma situação problemática ou as dificuldades que encontrou com um determinado pai.

O ciclo da reflexividade de Gibbs (citado em JASPER, 2003) apresenta um padrão de questões agrupadas em seis categorias diferentes a serem propostas em sucessão:

1. Descrição (o que aconteceu?);

2. Sentimentos (o que eu pensei e ouvi?);

3. Avaliação (o que foi positivo e negativo na experiência?);

4. Análise (que sentido posso dar à experiência e situação que foi criada?);

5. Conclusões (o que mais eu poderia ter feito?);

6. Plano de ação (se a situação surgir novamente, o que eu faria?).

A análise do evento ou episódio em que pretendemos desenvolver uma reflexão dentro da equipe educacional, portanto, começa a partir do pedido a cada membro do grupo para descrever da maneira mais detalhada possível o que aconteceu. Em seguida, mostram-se também a sua experiência emocional relacionada ao episódio, que é um elemento a ser considerado, pois pode permitir que se destaque significados diferentes daqueles destacados através de uma investigação racional. Segue a avaliação em termos dos aspectos negativos e positivos da experiência e a leitura do seu significado para se concentrar nas razões do que aconteceu. A reflexão se completa raciocinando sobre as possíveis repercussões operacionais, tanto em referência ao que poderia ser feito de forma diferente naquele contexto específico, como em hipóteses de ações diferentes no caso de situações semelhantes surgirem novamente.

O modelo proposto por Gibbs pode ser aplicado de várias maneiras, de fato "a reflexão pode ser conduzida entre si, isto é, em um nível substancialmente mental e meditativo, ou verbalmente, ou seja, conversando com outras pessoas sobre um evento considerado significativo. Depois, há uma outra área de desenvolvimento da reflexividade e que é representada pela escrita" (SICORA, 2010, p. 114). 
Deste ponto de vista, um instrumento de escrita reflexiva extremamente útil e absolutamente sustentável em termos de tempos e cargas de trabalho que comporta é o diário de bordo. Uma ferramenta que permite documentar e construir uma memória da experiência cotidiana para poder fazer dela o tema de uma reflexão retrospectiva também dentro do grupo de trabalho. É, portanto, questão de deixar um rastro sistemático do que acontece diariamente, sem evitar explicitar a maneira como os eventos foram interpretados e a ressonância que eles tiveram no nível emocional, analisála mais tarde e aumentar os níveis de consciência de suas ações.

O diário, que requer tempos regulares de escrita, pode conter "vários tipos de dados" (MORTARI, 2003, p. 94): descrições detalhadas de situações também realizadas através do uso da observação, narrações de eventos e episódios que aconteceram e das circunstâncias em que aconteceram, avaliações que consideram a maneira de se comportar em momentos particulares, intuições que se podem ter em certas ocasiões e que é útil anotar, reconstruções de suas experiências emocionais e hipóteses sobre possíveis intervenções ou estratégias relacionais a serem colocadas no campo no futuro. A análise do que está escrito no diário pode solicitar reflexões que envolvam tanto as implicações teóricas de suas práticas, tanto elementos de dúvida quanto questões que se querem investigar ou ações eventuais que possam contribuir para melhorar a situação em exame.

O diário constitui, no entanto, uma ferramenta essencial para criar a oportunidade de um confronto dialógico construtivo sobre relacionamentos e práticas dentro da equipe educacional. Pode-se dizer, de fato, que "não se aprende o pensamento crítico fora de um espaço público [...]. Quando outros ouvem nossos relatórios e podem refletir sobre eles, é possível encontrar-se confrontados com outras interpretações diferentes das nossas, que nos empenham a construir uma nova versão interpretativa de nossa ação, que é o pressuposto para elaborar modelos alternativos de prática" (MORTARI, 2003, p. 110-111).

O diário de bordo, bem como outras ferramentas para a escrita reflexiva, representa, portanto, uma maneira efetiva de investigar e analisar criticamente a relação educacional, solicitando uma prática reflexiva real dentro do grupo de trabalho. Nesse 
sentido, as duas abordagens propostas, que valorizam os processos de observação $e$ narração através de diferentes ferramentas, constituem formas diferentes e complementares para explorar e divulgar os significados dos componentes relacionais do contexto, ativando dinâmicas de confronto entre os membros da equipe que podem levar a uma compreensão mais profunda das implicações formativas de suas atividades de comunicação e, consequentemente, à construção de um estilo educacional mais compartilhado.

\section{Referências}

Balduzzi Lucia, Manini Milena (a cura di) (2013), Professionalità e servizi per l'infanzia, Roma, Carrocci editore.

Becchi Egle (1978). "Il sapere che entra nella scuola”. Riforma della scuola, 6/7, 9-11.

Bove Chiara (2009), Ricerca educativa e formazione: contaminazioni metodologiche, Milano, Franco Angeli.

Bowlby John (1969), Attachment and loss: vol. 1. Attachment, Basic Books, New York, trad. it. Boringheri, Torino, 1989.

Cabell Sonia et al. (2013), "Variation in the effectiveness of instructional interactions across preschool classroom settings and learning activities", in Early Childhood Research Quarterly, 28, 4, pp. 820-830.

Cadima Joana, Leal Teresa, Burchinal Margaret (2010), "The quality of teacher-student interactions: associations with first graders' academic and behavioral outcomes", in Journal of School Psychology, 48, pp. 457-482.

Caggio Francesco, Mantovani Susanna (a cura di) (2004), Famiglie, bambini, educatrici: esplorazioni del consueto, Azzano San Paolo (Bg), Edizioni Junior. 
Cappa Francesco (2014). "Introduzione", in Cappa Francesco (a cura di), Metodo e qualità dell'esperienza scolastica, Milano, Franco Angeli.

Cescato Silvia, Bove Chiara, Braga Piera (2015), "Video, formazione e consapevolezza. Intrecci metodologici”, in Form@re, 2, 15, pp. 61-74.

Colicchi Enza (2005). "Note su intenzionalità educativa e razionalità", in Cambi Franco (a cura di), Le intenzioni nel processo formativo, Tirrenia (Pisa), Edizioni del Cerro.

Connell James, Wellborn James (1991), “Competence, autonomy and relatedness: A motivational analysis of self-system processes", in Megan Gunnar, Alan L. Sroufe (a cura di), Minnesota symposium on child psychology, NJ Erlbaum, Hillsdale, v. 23, pp. 43-77.

Corazza Laura (2012), “Il video, un mediatore per l'apprendimento”, in Form@re, 79, 12, pp. 13-21.

Curby Timothy et al. (2009), "The relations of observed pre-k classroom quality profiles to children'achievement and social competence", in Early Education and Development, 20, pp. 346-372.

Dower Jason, Sabol Terri, Hamre Bridge (2010), "Teacher-Child interactions in the classroom: toward a theory of whitin and cross-domain links to children's developmental outcomes", in Early Education and Development, 21, 5, pp. 699-723.

Downer Jason et al. (2012), "A course on effective teacher-child interactions: effects on teacher beliefs, knowledge, and observed practice", in American Educational Research Journal, 49, 1, pp. 88-123.

Fabbri Loretta (2007). Comunità di pratiche e apprendimento riflessivo. Roma, Carocci. Franceschini Giuliano, Borin Paolo, Il curricolo nella scuola dell'infanzia, Roma, Carocci.

Gibbs Graham (1988), Learning by doing: a guide to teaching and learning methods, Oxford, Further Education Unit, Oxford Polytechnic, cit. in Jasper Melanie (2003), Beginning reflective practice (Foundation in nursing and health care), Cheltenham, Nelson Thornes Ltd.

Goldman Ricki, Pea Roy, Barron Brigid, Derry Sharon J. (a cura di) (2007), Videoricerca nei contesti di apprendimento. Teorie e metodi, trad. it. Raffaello Cortina, Milano, 2009. Hamre Bridge et al. (2013), "Teaching through interactions. Testing a Developmental Framework of Teacher Effectiveness in over 4.000 classrooms", in The Elementary School Journal, 113, 4, pp. 462-487.

Hanks William (1991), “Prefazione”, in Lave Jean, Wenger Etienne, L'apprendimento situato, trad. it. Erickson, Trento, 2006.

Hinde Robert (1981), “Commentary”, in Human Development, 33, pp. 283-288. 
LoCasale-Crouch Jennifer et al. (2007), "Observed classroom quality profiles in statefunded pre-kindergarten programs and associations with teacher, program, and classroom characteristics", in Early Childhood Research Quarterly, 22, 1, pp. 3-17.

Manghi Sergio (2004), La conoscenza ecologica, Milano, Raffaello Cortina Editore.

Mantovani Susanna (a cura di) (1989), La scuola del bambino: commento ai nuovi orientamenti per la scuola materna della Commissione Scurati, Bergamo, Juvenilia.

Mortari Luigina (2003), Apprendere dall'esperienza, Roma, Carocci.

Mortari Luigina (2009), Ricercare e riflettere. La formazione del docente professionista, Roma, Carocci.

Neri Sergio, (2001), Guardare vicino e lontano. Qualità e prospettive della scuola dell'infanzia, Milano, Fabbri editori.

Pakarinen Eija et al. (2010), "A Validation of the Classroom Assessment Scoring System in Finnish Kindergartens”, in Early Education and Development, 21, 1, pp. 95-124.

Pakarinen Eija et al. (2012), "A Validation of the Early Childhood Classroom Observation Measure in Finnish and Estonian Kindergartens", in Early Education and Development, 23, pp. 323-350.

Palmieri Cristina (2014). "Metodo e qualità dell'esperienza scolastica: percorsi di ricerca e formazione", in Cappa Francesco (a cura di), Metodo e qualità dell'esperienza scolastica, Milano, Franco Angeli.

Parola Alberto, (2012), Regia educativa. L'insegnante osservatore tra percorsi “in ricerca": linguaggi e strategie, Roma, ARACNE editore.

Pattison Cassandra et al. (2014), "Emotional Climate and Behavioral Management during Sleep time in Early Childhood Education settings", in Early Childhood Research Quarterly, 29, pp. 660-668.

Pianta Robert (1999), La relazione bambino-insegnante: aspetti evolutivi e clinici, trad. it. Raffaello Cortina, Milano, 2001.

Pianta Robert et al. (2005), "Features of Pre-Kindergarten Programs, Classrooms, and Teachers: Do they predict observed classroom quality and child-teacher interactions?", in Applied Developmental Science, 9, 3, pp. 144-159.

Pianta Robert, La Paro Karen, Hamre Bridge (2008), Classroom Assessment Scoring System (CLASS) manual, Brookes, Baltimore. 
Pianta Robert, Hamre Bridge (2009), "Conceptualization, Measurement and Improvement of Classroom Processes: standardized observation can leverage capacity", in Educational Researcher, 38, 2, pp. 109-119.

Salminen Jenni et al. (2012), "Observed Classroom Quality Profiles of Kindergarten Classrooms in Finland", in Early Education and Development, 23, pp. 654-677.

Savio Donatella (2011), "Il gioco e la partecipazione del bambino: una sfida educativa e i suoi nodi”, in Anna Bondioli, Donatella Savio (a cura di), Partecipazione e Qualità. Percorsi di condivisione riflessiva nei servizi per l'infanzia di Modena, Parma, Edizioni Junior-Spaggiari Edizioni, pp. 205-251.

Sicora Alessandro (2010), Errore e apprendimento nelle professioni di aiuto, Santarcangelo di Romagna (RN), Maggioli.

Terzi Nice (2017), "Cura e relazione educativa: promuovere l'apprendimento nella prospettiva dello o/6", in Claudia Lichene (a cura di), Conoscere lo 0-6, I Quaderni, 3, Bergamo, Zeroseiup edizioni, pp. 53-57.

Tochon Francois Victor (2009). "Dai video-casi alla video-pedagogia. Una cornice teorica per il video-feed-back e la riflessione con i video nella pratica della ricerca pedagogica". In Ricki Goldman, Roy Pea, Brigid Barron, Sharon Derry, Videoricerca nei contesti di apprendimento.Teorie e metodi (pp. 83-101), Milano, Raffaello Cortina.

Vitiello Virginia, Hadden Sarah (2014), CLASS System. Implementation guide. Aligned improvement solutions, Charlottesville, VA, Teachstone.

Von Suchodoletz Antje et al. (2014), "A typical morning in preschool: Observations of teacher-child interactions in German preschools", in Early Childhood Research Quarterly, 29, pp. 509-519.

Universidade do Estado de Santa Catarina - UDESC Programa de Pós-Graduação em Educação - PPGE 